ARTICLE HISTORY: Received: October 12, 2021 Accepted: December 06, 2021 Published: December 13, 2021

\title{
MODERN CONCEPTUALIZATION OF THE WAYS OF DEVELOPMENT OF MUSICAL THINKING OF THE STUDENT-MUSICIAN.
}

\author{
Glebov Anna Alexandrovna \\ Assist.univ. master of music, assist. univ., \\ Alecu Russo State University in Balti, R. Moldova
}

\begin{abstract}
The author of this investigation discusses the importance of musical-Choral Art in the formation of the student-musician. The main focus is on the analysis of the concept of "musical thinking". One of the definitions of this concept is given from the point of view of the internalization of music, as the mechanism of functioning of musical thinking. In this context this phenomenon is analyzed and characterized from various points of view. The author concludes that internalization is an indicator of the development of musical thinking of the student's personality, and its development, as an integral phenomenon, opens up unlimited opportunities for the formation of creative abilities and the formation of the student's spiritual culture.

Key words: musical thinking, interiorization of music, principles and methods, pedagogy of hearing, vocal and choral performance, student-musician, music school.
\end{abstract}

The problem of artistic education belongs to the number of everlasting urgent problems, because each historical stage in the development of society, forming its ideal, makes new demands on a person. Also, the problems of musical education at the present stage are determined by the nature and content of the conditions that characterize the spiritual life of modern society. The present stage in art pedagogy is characterized by the presence of basic concepts, scientific and methodological principles, methods of artistic education and education of children formed and developed by specialists.

Such problems include the problems of musical education and education in children's music school, where, in addition to the valuable musical art, choral art also participates in the implementation of the main common task - in transforming a person and shaping his relationship to the world and himself.

Turning to the study of art education / education, educational scientists have identified various ways of introducing children to art. One of these avenues is through the use of certain specific techniques, such as awakening artistic interests; mastering the skills of artistic and creative activity; emotional impact, the method of emotional drama, heuristic method (D. Kabalevsky, E. Abdulin). The method of interiorization of music (E. Nazaikinsky, V. Medushevsky) as a factor in the spiritual transformation of the personality [4], which has recently been attached to, is also included in them. great importance in musical education and education.

To know the world in connection with a person's relationship to it means to simultaneously evaluate it. After all, personal relationships certainly contain assessments that express the importance of certain phenomena for a given person and serve as orientation milestones for him in his interaction with people around him. Thus, through the art of music, the student musician becomes both a performer and a creator, as well as a listener and connoisseur of music. At the same time, the art of music fulfills its spiritual mission, thereby orienting the student's personality towards the correct and adequate solution of life circumstances.

Choral music, like any other kind of musical art, is addressed to cognition, to experience, emotional perception: it evaluates and mentally creates qualities that it intends to instill in its performers and listeners. Thus, in the process of pupils' choral activity, the cognitive, value-oriented, constructive and formative functions of music merge together. Also, its sides are firmly connected with creative activity, which in the choral performance takes on various aspects, including the interiorization of the music performed. The basis for the formation of a performing choral culture, as part of the spiritual culture of a student, is a developed musical thinking. According to a number of scientists (B. Asafiev, E. Nazaikinsky, V. Medushevsky, A. Sokhor, M. Mikhailov, I. Gajim), musical thinking consists of a number of mechanisms, such as: intonation reserve, internal auditory background, interiorization of music.

In studies of musicology, cultural studies and psychopedagogy, musical thinking is viewed as productive creative thinking, reflecting various types of human activity: from reflection, perception to creation and communication. The founder of the theory of musical thinking is the Russian musicologist B. Asafiev, who substantiated the intonation theory of music. Another Russian musicologist A. Sokhor considers the basic laws of musical thinking as a social phenomenon. We are talking about musical thinking as a musical language, which is characterized by musical logic. The scientist emphasizes that musical thinking develops in the process of musical activity.

Russian teacher-researcher M. Aranovsky [1], considers musical thinking as a type of communicative activity. At the same time, he interprets a piece of music as a communicant, i.e. audio message addressed to the listener. The transmission of information is carried out through the musical language. The musical language is the musical message. 
The works of another Russian scientist V. Medushevsky [6] contain the main conclusion that reveals the essence of musical thinking - this is the formation of the spiritual world of a person, the education of his feelings. And yet the path to the definition of musical thinking lies through the general forms of the philosophical definition of thinking as the highest measure of active reflection of objective reality.

Modern researches of Russian music teachers V. Beloborodova, G. Rigina, Y. Aliev, speak about the connection between the development of thinking and the formation of spirituality: "Musical thinking as a particular type of thinking is genetically connected with all mental, spiritual human activity" [3].

Understanding the mechanisms of musical thinking served as the basis for E. Nazaikinsky's research on the psychology of music perception and the role of concepts in this process; V. Medushevsky on the theory of duality of musical form, which allows us to distinguish two main aspects in intonation form: analytical and pro-intonation; A. Sokhora on the problems of the sociology of art; L. Mazel and V. Zuckerman on the analysis of musical form, I. Gazhim on the theory of interiorization of music.

According to V. Medushevsky, the main mechanism of musical thinking is, "immersion in the intonational subjectivity of the work, allows you to penetrate into its inner world in the processes of creativity, performance and perception. To think intonationally means to hear life in sounds. This is how the effect of artistic perception, specific to art, is realized in music, which in aesthetics and art history is called "transfer" and which is equally characteristic of the composer, performer, listener "[6]. This determines the existence of a musical intonation language, for all the richness of musical means, the variety of elements of music is intonational in nature.

The Russian scientist M. Mikhailov, in his methodology for the development of musical thinking, identifies some of the mechanisms of its development, such as: intonation reserve, internal auditory background, while putting them forward as the fundamental conditions of "creative, performing and listening thinking" [7].

According to the Moldovan scientist I. Gajim, the simplest structural mechanisms, where the interiorization of music is transmitted, perceived through musical thinking, are: pitch, rhythm, tempo, loudness, timbre and harmony. All this forms the "spiritual state that encompasses a person when he penetrates, listening, performing or composing music" [10]. Musical thinking at this level proceeds according to the laws of physiology, that is, at the level of sensations: fastslow, alarmingly calm, loud-quiet. Thus, we can conclude that interiorization is one of the internal mechanisms of musical thinking, connecting with external objects and components, with elements of musical life and culture.

At the pedagogical level, musical thinking is considered as a component of musical education in general. The purpose and meaning of musical upbringing / education at the present stage in a music school is clearly indicated: the formation of a student's musical performance culture as a part of his spiritual culture. Forming a personality, we develop its intellect, its individual abilities, form its consciousness, develop thinking. All kinds of musical activity are directed and regulated by the artistic musical consciousness. Thanks to the processes of artistic musical thinking, artistic musical consciousness is formed and develops. Artistic thinking and various mechanisms of its manifestation, in particular the interiorization of music, form spiritual and moral qualities. Thus, musical thinking and the interiorization of music are the process of the subject's mental activity, modeling his relationship to reality in intonated sound images. The subject of relations in the process of modeling is a concrete personality, in the structure of which musical thinking is organically linked with all psychological characteristics. It arises in the process of active, aesthetically colored interaction with sound reality.

In this article, as the basis for the development of musical thinking in a children's music school, we consider vocal and choral activities in a choral art lesson. According to the modern curricular concept, the goal of vocal and choral activity is the correct and harmonious development and education of the student's personality. This goal is determined by the spiritual content of the singing process itself, aimed at the value-semantic comprehension of the surrounding reality and oneself.

As a methodological basis for the development of musical thinking through interiorization, I. Gajim offers the following methods of vocal and choral activity: "thoughtful singing", plastic intonation with simultaneous mental tracking / mental "performance" (with closed eyes) of the sound line (vox mentis - mental voice), "meditative" listening, humming tunes / motives / melodies in an undertone with a gradual transition to "mute" singing, etc. [4]. Thus, giving each of them a spiritual reflection, and therefore an interiorized action.

It is worth noting that, as before, most of the choir leaders do not have a methodological culture, including the use of the method of interiorization in the formation of musical thinking. In this context, the scientist M. Kushnir identified the following didactic principles that contribute to the development of musical thinking through the interiorization of music in the process of vocal and choral activity:

- The principle of integrity;

- The principle of vigorous activity;

- The principle of creativity;

- The principle of mental hearing. [5]

At the same time, the author of these principles notes that "as students become involved in the process of mental listening, reading already begins to precede singing" [5]. In the process of vocal and choral activity, these principles are realized and implemented in interaction. 
M. Mikhailov identifies the following conditions for the development of musical thinking:

- intonation stock;

- Internal hearing reserve.

These conditions, according to the author, are inherent in any kind of musical thinking, both creative, performing and listening" [6]

Vocal and choral performance. as a consequence of the developed musical thinking. is carried out at all stages of work and implements the following tasks:

- mental reproduction of music by heart;

- reading from notes with the maximum approximation of the mental sound to the real one;

- vocal and choral performance of the work;

- alternation of mental and real performance.

So, in choral lessons, through the use of methods and mechanisms for the development of musical thinking, the educational process lends itself to analysis and comprehension, and the level of musical thinking becomes an indicator of the development of the spiritual personality as a whole. Its directed development in the process of vocal and choral activity opens up wide opportunities for creating value attitudes, creative abilities and for the development of the spiritual culture of students.

\section{Bibliography:}

1. Aranovskiy MG, Problems of Musical Thinking. Digest of articles. Publishing house "Music". Moscow. 1974.S. 15-19. (In Russian).

2. Asafiev BV, Musical form as a process. Publishing house "Music". Leningrad. 1971.S. 26-31. (In Russian).

3. Beloborodova VK, Rigina GS, Aliev Yu. B. Musical perception of schoolchildren. Edited by M.A.Rumer. Publishing house "Pedagogy,". Moscow. 1975.S. 112-122. (In Russian).

4. Gajim IF, Music as a great pedagogy. Music and pedagogical education at the turn of the XX and XXI centuries. Materials of the VIII International Conference. Moscow. 2004.S. 9-10. (In Russian).

5. Kushnir MB, Comprehensive methodology for the development of musical thinking. Problems of the development of the system of music education: Sat. tr. no. 87 / GMPI them. Gnesins. Moscow. 1986.S. 3-9. (In Russian).

6. Medushevsky VV, On the patterns and means of artistic influence of music. Publishing house "Music". Moscow. 1976.S. 119-156. (In Russian).

7. Mikhailov, M.K. Methodological culture of a teacher-musician. On some psychological mechanisms of musical thinking. Ed. E.B. Abdullina. Publishing house "Academy". Moscow. 2002.S. 66-98. (In Russian).

8. Orlova EM, Asafiev's intonation theory as a teaching about the specifics of musical thinking: History. Becoming. Essence. Publishing house "Music". Moscow. 1984.S. 45-78. (In Russian).

9. Sokhor AN, Social conditioning of musical thinking and perception // Problems of musical thinking. Publishing house "Music". Moscow. 1974.S. 41-50 (In Russian).

Gagim I.F., Ştiinţa şi arta educaţiei muzicale. Editura ARC. Chişinău. 1996. C. 19-27. (In Romanian). 